\title{
Developing socio-cultural competencies of students at professional educational institutions
}

\author{
$O I$ Vaganova $^{l}$, $Z h V$ Smirnova $^{l,} *, A V$ Chanchina $^{l}$, $O V$ Korobova $^{2}$, and $V G$ Lizunkov ${ }^{3}, G$. $A$. Stepanova ${ }^{4,5}$ \\ ${ }^{1}$ Minin Nizhny Novgorod State Pedagogical University, 9, Chelyuskin str, 603004, Nizhny Novgorod, Russia \\ ${ }^{2}$ Volgograd State University, 100, Universitetsky prosp, 400062, Volgograd, Russia, \\ ${ }^{3}$ Yurga Institute of Technology (Branch) of National Research Tomsk Polytechnic University, Department of Digital Technology, 36 , \\ Lenin Ave, 634050, Tomsk, Russia. \\ ${ }^{4}$ Humanities Institute of Northern Studies of Ugra State University, 16, st. Chekhov, 628012, Khanty-Mansiysk, Russia \\ ${ }^{5}$ Institute for Humanities Education and Sports of Surgut State University, 1, Lenin Ave., 628412, Khanty-Mansiysk, Russia
}

\begin{abstract}
The article deals with the development of socio-cultural competencies in students of pre-school educational institutions. Based on the analysis of scientific literature, the authors reveal the essence of sociocultural competences in general and highlight their significance for pupils. Based on the fact that sociocultural competence is an integrative characteristic of a person who presupposes knowledge in various social and cultural spheres, includes the ability and willingness to interact with other people in different life ranges, the ability to use information resources for creative meaning in the information space, the authors present a study conducted over two years in a municipal budgetary pre-school educational institution kindergarten "cloud". For a full-fledged study, the article analyzes the level of formation of sociocultural competences in 2017 (before the introduction of the model) and in 2018 after its implementation. The study is carried out with the grant support for young scientists - candidates of sciences, number MK-313.2019.6, issued by the President of the Russian Federation Comparison of indicators allowed one to establish the degree of effectiveness of the proposed model. To identify the degree of formation of competencies, the authors proposed several levels: low, medium and sufficient.
\end{abstract}

\section{Introduction}

With the emergence of socio-economic changes, their unpredictability, intensive growth of information sources, the emergence of new ideas about the culture of society as a whole and the individual, their relationships, patterns of social behavior, it became necessary to change the ideas of society about the goals, objectives and results of modern education [1]. Among the principles of the Federal State Educational Standard for Preschool Education, it is necessary to highlight first and foremost the construction of educational activities based on the individual characteristics of each child for more comfort and its development as a person and selfrealization at the next levels of education [2]. In addition, one of the main tasks of preschool education is the formation of a child in society, the cultivation of its cultural behavior [3]. This task is impossible without creating a sociocultural environment. The federal state educational standard reflects the requirement of its formation.

In modern conditions, close attention is paid to changes in the Russian education system, where the priority goal is the development of an individual who is ready for proper interaction with the outside world, for self-education and self-development [4]. Competences became the central concept, value, goal and result around which modern education is built [5]. The relevance of the work is to identify the most effective way of sociocultural competence development in modern educational conditions $[6,7,8]$.

\section{Methodology}

The authors developed a model for the formation of sociocultural competences. Ball conducted an experiment on its introduction into the educational space of the municipal budgetary preschool educational institution Oblachko kindergarten. The experiment was conducted for 2 years (2017-2018). It was attended by 2 groups of children (60 people). In 2017, in this kindergarten (prior to the introduction of the model), a special technique was conducted, with the help of which rather low results of sociocultural competence formation were identified. The technique included several situations and questions to them. The activity of the participants was reduced to the topic "How I would behave in this situation" $[9,10]$.

In 2018 (after the introduction of the model) the same methodology was used, but the results were much higher, therefore, the level of formation of sociocultural

\footnotetext{
* Corresponding author: z.v.smirnova@mininuniver.ru
} 
competences in children through the introduction of the model increased [11].

\section{Results and discussions}

There are quite a few definitions of the concept "sociocultural competence" in the scientific literature. E.N. Solovova believes that this is an element of foreign language communicative competence. E.G. Azimov and A.N. Schukin represent the content of this competence in the form of four elements:

- sociocultural knowledge;

- communication experience, its style and adequate interpretation of cultural phenomena [12];

- personal attitude to the facts of culture;

- possession of ways to use the language [13].

Since sociocultural competence is a complex phenomenon, we decided to single out the following definition [14]. Sociocultural competence is called the integrative personality characteristic, which presupposes knowledge in various social and cultural spheres, includes the ability and willingness to interact with other people in different life ranges, the ability to use information resources for creative meaning in the information space [15].

We have developed a model for the formation of sociocultural competencies of students of an educational institution [16]. To ensure effectiveness, the model contains interrelated components:

- target (includes the goal and the theoretical and methodological basis as the competence and culturelogical approaches, as well as the principles of choice, controllability and focus) [17];

- informative (represented by fiction, play, speech, movement, labor, music, visual arts and fiction);

- procedural (contains methods: games, conversations, projects, storytelling, observation, reveals the means: plot pictures with different situations, board games, cards for individual work, presentations, models and models; forms: quizzes, parties, concerts, author exhibitions, holidays for children and their parents, reviews, research and creative, role-playing forms) $[18,19]$;

- effective (the predicted result is an increase in the level of formation of the sociocultural competences of preschoolers).

Thus, the students develop the ability to communicate and communicate freely, they develop the ability to listen to the interlocutor, to help him, to give in and control his own emotions in time [20].

Using the analysis of pedagogical experience, we identified the conditions for the effectiveness of our proposed model:

- the need to involve adults in interactive activities with children. The position of an adult is indicated as an employee partner. So, the child comprehends the main types of interaction with adults;

- organization of an individual approach to each child;

- providing conditions for the development of cognitive and creative abilities;
- maintaining the activity of children;

- creation of conditions for the implementation of learned methods of activity;

- involvement of each pupil in the learning process.

To check the degree of formation of competencies, we distinguish several levels:

-sufficient;

- average;

- low [21].

Their description is presented in table 1 .

Table 1. Levels of sociocultural competences development

\begin{tabular}{|c|c|}
\hline Level & Description \\
\hline Low & $\begin{array}{l}\text { In the process of learning a child: } \\
\text { - does not finish the started business; } \\
\text { - does not regret taking part in the life of } \\
\text { the group; } \\
\text { - does not know how to listen and listen to } \\
\text { someone else's opinion; } \\
\text { - does not want to establish contacts in the } \\
\text { group; } \\
\text { - inattentive; } \\
\text { - hard to remember information. }\end{array}$ \\
\hline Average & $\begin{array}{l}\text { In the process of learning a child: } \\
\text { - brings to the logical conclusion only those } \\
\text { matters that are of interest to him; } \\
\text { - does not want to take an active part in the } \\
\text { life of the group, in group activities; } \\
\text { - knows how to listen, but considers his } \\
\text { opinion the only correct one; } \\
\text { - it is difficult to establish contacts in the } \\
\text { group, with the help of a teacher; } \\
\text { - remembers information well. }\end{array}$ \\
\hline Sufficient & $\begin{array}{l}\text { In the process of learning a child: } \\
\text { - tries to bring all the started things to the } \\
\text { end; } \\
\text { - actively participates in the life of the } \\
\text { group; } \\
\text { - listens to someone else's opinion and } \\
\text { knows how to listen to it; } \\
\text { - open to new contacts, easily makes } \\
\text { friends; } \\
\text { - remembers the information well, takes an } \\
\text { active interest in it. }\end{array}$ \\
\hline
\end{tabular}

In 2017, in the Kindergarten "Oblachko" with the help of the method "How I would act in this situation" the level of formation of sociocultural competences was revealed. Pupils were offered several situations in which they needed to answer questions [22, 23, 24].

1 situation. Mom does the house cleaning. Would you help her? What would you do? Do you think Mom would like you to help her?

2 situation. You were treated to chocolate. Would you share it with your friends?

3 situation. You accidentally noticed that a basket with apples was being sent on the grandmother's street. Would you help her pick apples? Why?

4 situation. There are few places on the bus, you took one of the remaining places, after a few stops there were no seats left, an elderly woman comes in at the next stop, would you give up her place? Why?

Depending on the situation, questions may vary and be supplemented. 
In 2017, after conducting this game among students, an average and low level of formation of sociocultural competences was revealed [25, 26, 27].

Chart 1 shows the results of 2017.

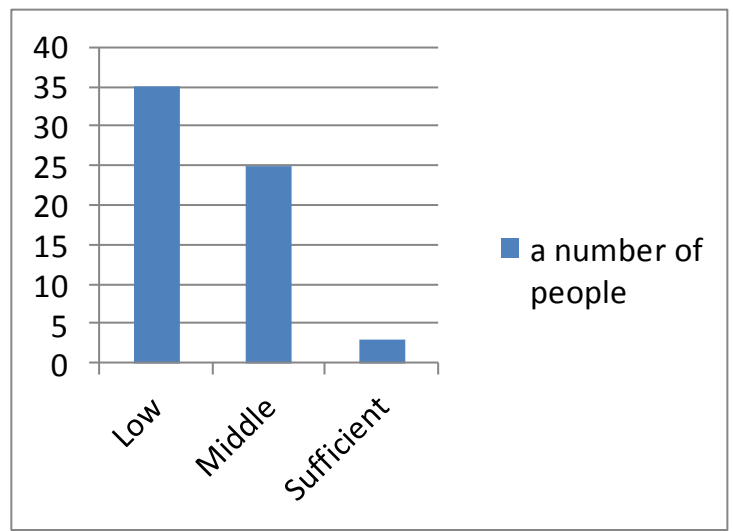

Diagram 1. The level of formation of sociocultural competences in the Kindergarten "Cloud" before the introduction of the model [28, 29].

In 2018, after the introduction of the model, a study was conducted again with a constant number of people and age group of participants. The results were significantly higher than the year 2017. They are presented in the diagram.

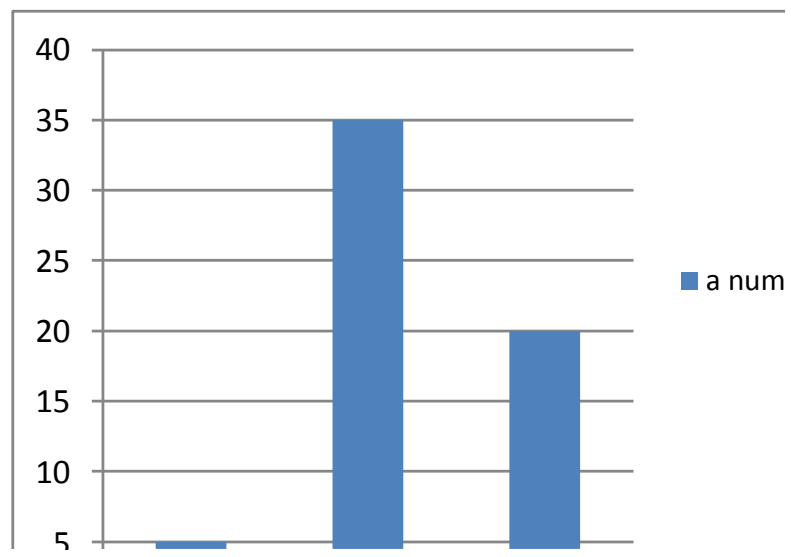

Diagram 2. The level of sociocultural competences development in the Kindergarten "Oblachko" before the introduction of the model [30].

In 2018, after the introduction of the model, a study was conducted again with a constant number of people and the age group of participants. The results were significantly higher than in the year 2017. They are presented in a diagram.

\section{Conclusions}

The experiment showed effectiveness. The developed model allows you to imagine the formation of sociocultural competences among preschool children as a process that can be adjusted in accordance with a given goal, and therefore to manage the formation of the competencies in question more effectively. The study is carried out with the grant support for young scientists candidates of sciences, number MK-313.2019.6, issued by the President of the Russian Federation After the introduction of this model in the preschool education institution "Oblachko", the formation of sociocultural competences increased. This means that the model is effective and can be applied in other institutions of preschool education.

The study is carried out with the grant support for young scientists - candidates of sciences, number MK-313.2019.6, issued by the President of the Russian Federation.

\section{References}

1. M.N. Bulaeva, O.I. Vaganova, M.N. Gladkova, Activity technologies in a professional educational institution, Baltic Humanitarian Journal 7, 3 (24), 167-170 (2018). URL: https:/elibrary.ru/item.asp?id=36237878.

2. J.V. Smirnova, K.A. Kochnova, Training of employees of service enterprises using information technologies, Vestnik of Minin University 7, 1 (26), 5 (2019).

3. O.I. Vaganova, L.K. Ilyashenko, The main directions of implementation technologies of student-centered education in high school, Vestnik of Minin University 6, 3, 2 (2018). DOI: 10.26795/2307-1281-2018-6-3-2.

4. N. V. Kamenez, E. A. Aleshugina, O. I. Vaganova, Z. V. Smirnova, A. V. Chanchina, Competencyoriented improvement of an additional language educational program in technical higher education, International Journal of Mechanical Engineering and Technology 9(11), 1137-1145 (2018).

5. Z.V. Smirnova, O.I. Vaganova, D.A. Loshkareva, E.A. Konyaeva, M.N. Gladkova, Practice-oriented approach implementation in vocational education, IOP Conference Series: Materials Science and Engineering 483 (1), 012003 (2019).

6. O. I. Vaganova, L. N. Zanfir, Z. V. Smirnova, E. A. Chelnokova, S. N. Kaznacheeva, A. Maseleno, On the linguistic training of future teachers of unlike specialties under the conditions of Russian professional education, International Journal of Engineering and Technology (UAE) 7(4), 40904095 (2018).

7. M.L. Gruzdeva, Z.V. Smirnova, Z.V. Chaikina, O.V. Golubeva, O.T. Cherney, Using internet services in teaching methodology, Lecture Notes in Networks and Systems 57, 1193-1199 (2019).

8. L. K. Ilyashenko, O. I. Vaganova, Z. V. Smirnova, M. L. Gruzdeva, A. V. Chanchina, Structure and content of the electronic school-methodical complex on the discipline "mechanics of soils, foundations and foundations", International Journal of Mechanical Engineering and Technology 9(4), 1088-1096 (2018).

9. L.K. Ilyashenko, Z.V. Smirnova, O.I. Vaganova, E.A. Chelnokova, S.N. Kaznacheeva, Methods of conducting practical training on the subject "power 
sources for welding", International Journal of Mechanical Engineering and Technology 10 (2), 908-917 (2019).

10. N. V. Kamenez, O. I. Vaganova, Z. V. Smirnova, M. N. Bulayeva, E. A. Kuznetsova, A. Maseleno, Experience of the use of electronic training in the educational process of the Russian higher educational institution, International Journal of Engineering and Technology (UAE) 7(4), 40854089 (2018).

11. S. S. Ivanova, E. V. Bystritskaya, I. Y. Burkhanova, et al. Physical Culture Teacher Professional Activity Problems in Polyethnic Educational Organization, Eurasian journal of analytical chemistry 12 (7B), 1615-1620 (2017).

12. Prokhorov MP, Vaganova O.I. Design and implementation of educational event in professional training of future managers, Bulletin of the Minin University 7, 1 (26), 4 (2019).

13. A. A. Fedorov, E. Y. Ilaltdinova, S. V. Frolova, Pedagogical talent: Psychological and pedagogical solutions for identification, selection, and support, Perspektivy Nauki i Obrazovania 37(1), 262-274 (2019). DOI:10.32744/pse.2019.1.19

14. E.V. Myalkina, E.P. Sedhyh, V.A. Zhitkova, V.A. Vaskina, O.I. Isaykov, University resource center as an element of social development of the region, Vestnik of Minin University 6 (3), 1 (2018). DOI: 10.26795/2307-1281-2018-6-3-1.

15. Fedor Nikolai, History, Archives, Studies of Memory: Disciplinary Politics and the Struggle for Authority, Novoe literaturnoe obozrenie 148, 321326 (2017).

16. Fedor Nikolai, Igor Kobylin, American trauma studies and the limits of their transitivity in Russia heart-to-heart talks with veterans of local conflicts, LOGOS 5, 115-136 (2017).

17. A. Pavlov, A. Kindaev, I. Vinnikova, E. Kuznetsova, Crop insurance as a means of increasing efficiency of agricultural production in Russia, International Journal of Environmental and Science Education 11(18), 11863-11868 (2016).

18. T. V. Perova, E. A. Kuznetsova, I. S. Vinnikova, S. N. Kaznacheeva, E. A. Chelnokova, Essence of the role and characteristics of the operating conditions of enterprises before and after the transition to market relations from a macroeconomic position, International Journal of Applied Business and Economic Research 15(12), 103-112 (2017).

19. N.S. Abramova, O.I. Vaganova, Zh.V. Smirnova, Organization of independent work in the implementation of a practice-oriented approach, The azimuth of scientific research: pedagogy and psychology 8, 1 (26), 13-15 (2019).

20. A.A. Skatova, D. S. Yambulatov, I. L. Fedyushkin, et al. Europium and Ytterbium Complexes with the Redox Active Acenaphthene-1,2-Diimine Ligand, Russian journal of coordination chemistry 44 (6), 400-409 (JUN 2018).
21. A. Fedorov, E. Zakablukovskiy, A. Galushkina, Making an urban university 'green': Uniting administration and students towards synergy. Uniting, E3S Web of Conferences 48 (2018). DOI: 10.1051/e3sconf/20184802007

22. Zh.V. Smirnova, O.G. Krasikova Modern tools and technologies for assessing learning outcomes. Vestnik of Minin University. 2018. Vol. 6, no. 3. P. 9. DOI: 10.26795/2307-1281-2018-6-3-9.

23. T.V. Anisimova, N.K. Prigarina, S.A. Chubay, The System of Rhetorical Argumentation in Discourse of Social Advertising, Vestnik Volgogradskogo gosudarstvennogo universiteta. Seriya 2. Yazykoznanie [Science Journal of Volgograd State University. Linguistics] 18 (2), 159-173 (2019). DOI: https:// doi.org/10.15688/jvolsu2.2019.2.14

24. Yu. Malushko, O. A. Maletina, V. A. Tsybanyova, The Model of Teaching Listening Skills to Postgraduates with Disabilities and Special Needs in the Educational Podosphere, Advances in Social Science, Education and Humanities Research (ASSEHR) 198, 275-279 (2018).

25. O. A. Frolova, A. V. Chanchina, N. V. Frolova, S. M. Shevchenko, E. A. Chelnokova, N. V. Bystrova, The organization of the rating system for assessing the quality of university students training, European Research Studies Journal 20, 549-556 (2017).

26. N.S. Abramova, O.I. Vaganova, Zh.V. Smirnova, N. V. Kamenez, Z. V. Smirnova, O. I. Vaganova, N. V. Bystrova, Ju. M. Tsarapkina, Development of Instructing Techniques in Professional Training, International Journal of Mechanical Engineering and Technology 10(02), 899-907 (2019).

27. Lubov K. Ilyashenko, Zhanna V. Smirnova, Olga I. Vaganova, Elena A. Chelnokova, Svetlana N. Kaznacheeva, Methods of Conducting Practical Training on the Subject "Power Sources for Welding", International Journal of Mechanical Engineering and Technology 10(02), pp. 908-917 (2019).

28. O. I.Vaganova, Zh. V. Smirnova, S. M. Markova, Zh. V. Chaikina, M. N. Bulaeva, Organization of partnerships for additional educational services on the example of the interaction of the educational institution with the health and cultural centre, Perspektivy nauki i obrazovania - Perspectives of Science and Education 39 (3), 500-514 (2019). DOI: $10.32744 /$ pse.2019.3.38

29. E. Korobova, I. Kardovich, D. Mironova, M. Konysheva, Dependence of approaches and methods of foreign language teaching on socioeconomic factors, Advances in Social Science Education and Humanities Research (ASSEHR) 97, 119-124 (2017).

30. N.L. Shamne, E.Yu. Malushko, A.N. Shovgenin, Translation projects management - innovative decisions in training students-translators, Artium Magister 18 (1), 58-63 (2018). 